\title{
An audit of aneurysmal subarachnoid haemorrhage: earlier resuscitation and surgery reduces inpatient stay and deaths from rebleeding
}

\author{
P C Whitfield, H Moss, D O’Hare, P Smielewski, J D Pickard, P J Kirkpatrick
}

\begin{abstract}
Objective-To audit the outcome in patients with subarachnoid haemorrhage (SAH) after a change in management strategy.

Methods-A retrospective analysis of patients with aneurysmal subarachnoid haemorrhage over a 20 month period (phase 1) was followed by a prospective analysis of patients presenting during the next 20 months (phase 2 ) in which a protocol driven management regime of immediate intravenous fluid resuscitation and earlier surgery was pursued. Patients in this phase were grouped into those receiving early (within four days of subarachnoid haemorrhage) and late (after four days of subarachnoid haemorrhage) surgery. In phase 1,75 out of a total of 92 patients underwent surgery on (median) day 12. From phase 2, 109 patients out of a total of 129 underwent surgery on (median) day 4, 58 of which had their surgery within 4 days of the subarachnoid haemorrhage. Patients in each phase/group were well matched for demographic features, site of aneurysm, and severity of subarachnoid haemorrhage.
\end{abstract}

Results-The surgical morbidity and mortality were no different in the two phases (P<0.92; $\chi^{2}$ test). The management outcomes in the two phases of the study were also no different $(P<0.52)$. However, there was a significant reduction in the rebleed rate in patients undergoing surgery within four days of the subarachnoid haemorrhage in phase 2 $(P<0.0001)$ with an associated trend towards reduced incidence of postoperative ischaemia $(P=0.06)$ and mortality $(P=0 \cdot 11)$. Operating earlier in phase 2 of the trial resulted in a lower total hospital inpatient stay of $15.8(95 \%$ CI $13 \cdot 1-18 \cdot 5)$

University Department of Neurosurgery, Box 167, Block A Level 4, Addenbrooke's Hospital, Cambridge CB2 2QQ, UK $P$ C Whitfield

$\mathrm{H}$ Moss

D O'Hare

P Smielewski

J D Pickard

P J Kirkpatrick

Correspondence to:

Mr P J Kirkpatrick.

Received 25 April 1995 and in final revised form 18 October 1995

Accepted 27 October 1995
Keywords: Subarachnoid haemorrhage, timing of surgery, management outcome
Without surgery, $60-70 \%$ of patients with aneurysmal subarachnoid haemorrhage die within one year of the initial ictus. ${ }^{1-3}$ About $30 \%$ of patients die within the first 48 hours as a result of the catastrophic effects of the initial haemorrhage, or from a further bleed. ${ }^{45}$ In those who survive the initial insult, delayed cerebral ischaemia, and rebleeding are the main causes of morbidity and mortality in this condition.

The optimal management for aneurysmal subarachnoid haemorrhage remains controversial. Delayed surgery ( $>10$ days after subarachnoid haemorrhage) is historically associated with a lower operative morbidity and mortality than early surgery, but is accompanied by a high incidence of rebleeding which is usually fatal. ${ }^{6-10}$ In the multicentre British Aneurysm Nimodipine Trial the mean day of surgery was day 11.3 in the placebo and day 10.8 in the nimodipine treatment group, reflecting the preference for delayed surgery by many British neurosurgeons. ${ }^{11}$ Earlier surgery to secure the aneurysm neck reduces the occurrence of rebleeding but has traditionally been associated with increased operative morbidity. This may have been due to difficult operative conditions in patients with a swollen, non-autoregulating brain. Many reports of early surgery in subarachnoid haemorrhage exist in the medical literature ${ }^{12-19}$ teaching that if the consequences of delayed ischaemia can be suppressed by using hypervolaemic haemodilutional, hypertensive ( $\mathrm{HHH})$ therapy, ${ }^{20}$ a reduction of rebleeding can be translated into overall improved outcome. However, no difference in the management mortality between patients allocated to early or delayed surgery has been demonstrated..$^{91}$

The incidence of delayed cerebral ischaemia varies between $13.5 \%$ and $44 \% .59$ Cerebral vasospasm is believed to have a major role ${ }^{22}$ and reaches its highest incidence between days 7 and 10 after subarachnoid haemorrhage. ${ }^{23}$ The International Cooperative Study on the timing of aneurysm surgery showed that outcome was worse if surgery was performed during this period, a fact attributed to the effects of vasospasm. ${ }^{9}$ However, other factors may play a part in the pathogenesis of delayed ischaemia including hypotension, hypovolaemia, raised intracranial pressure, metabolic disturbances, and hypoxia.

Medical measures to counter the effects of cerebral ischaemia are available. Induced hypertension $^{24-27}$ and maintenance of a high fluid input ${ }^{26-28}$ have been established in the prevention and treatment of delayed cerebral 
ischaemia. The neuroprotective calcium channel antagonist nimodipine is also of proved efficacy in reducing the incidence of ischaemia after subarachnoid haemorrhage. ${ }^{11}$ Thus with additional improvements in neuroanaesthesia and operative microsurgical techniques, it is feasible that the morbidity associated with early surgery can be reduced.

As an initial approach to this hypothesis, we have conducted a retrospective review of the management and outcome in 92 patients with aneurysmal subarachnoid haemorrhage admitted to a regional neurosurgical unit during a 20 month period. We identified areas of concern and implemented a change in the management strategy with the objective of reducing delays in patient transfer, of improving perioperative medical resuscitation, and of reducing time to surgery. A subsequent prospective series of 129 patients was studied to establish the effect of these changes on the incidence of rebleeding, the development of postoperative ischaemia, duration of inpatient stay, and patient outcome after subarachnoid haemorrhage.

This study has appeared in abstract form..$^{29}$

\section{Clinical material and methods RETROSPECTIVE (PHASE 1) \\ Data collection}

All patients admitted during a 20 month period (February 1991 to September 1992) to a regional neurosurgical unit with aneurysmal subarachnoid haemorrhage were identified from the hospital inpatient diagnostic code database and operating theatre records. Patients with non-aneurysmal subarachnoid haemorrhage were excluded from the study. Clinical details were extracted from the hospital, neurosurgical, rehabilitation, and psychological records. These were age; sex; date of haemorrhage; date of admission to referring hospital; date of transfer to the neurosurgical unit, grade of subarachnoid haemorrhage on arrival in the neurosurgical unit (World Federation of Neurological Surgeons (WFNS) score) ${ }^{30}$; details of preoperative intravenous fluids; the day of angiography; and the number and location of any aneurysms present on the angiogram. In addition, the day and details of aneurysm surgery, the method of aneurysm treatment (clipping, wrapping or interventional radiological techniques), and the occurrence of intraoperative rupture were recorded.

The primary endpoint measures sought were: (a) incidence and day of any rebleed; (b) incidence of perioperative cerebral ischaemia; (c) outcome measured on the Glasgow outcome scale (GOS) ${ }^{31}$ at three months after subarachnoid haemorrhage; $(d)$ total length of hospital inpatient stay.

\section{PROSPECTIVE (PHASE 2)}

Data collection

From September 1992 to May 1994 a pro forma was utilised to record the same clinical data prospectively in all patients admitted to the neurosurgical unit with subarachnoid haemorrhage. The criteria for recording perioperative cerebral ischaemia and rebleeding were those used in the British Nimodipine Trial. ${ }^{11}$

\section{Perioperative resuscitation}

A policy of earlier referral to the regional neurosurgical unit was encouraged. Published evidence suggests that prophylactic hypervolaemic, hypertensive treatment may reduce the incidence of postoperative ischaemia..$^{262732}$ A fluid protocol of alternating colloid and crystalloid $(2.51$ per day) was therefore advised at diagnosis and continued/ implemented on arrival in the neurosurgical unit to ensure an adequate intravascular volume. For patients in WFNS grade 3-5, fluid replacement was guided by central venous monitoring ( $\mathrm{CVP} 8-10 \mathrm{~cm} \mathrm{H}_{2} \mathrm{O}$ ). Based on previous studies systolic arterial blood pressure (SABP) was maintained above $130 \mathrm{~mm} \mathrm{Hg}$ during the preoperative period. ${ }^{26} 272$ Postoperatively SABP was raised to $160 \mathrm{~mm} \mathrm{Hg}$ using inotropes if necessary. Hypervolaemic, hypertensive therapy was continued for 48 hours, or longer, in the event of any ischaemic deficit.

Prospective definition of early and late surgery The timing of angiography and surgery was determined by the transfer and individual neurosurgical practice. Two subgroups of patients were defined: those undergoing surgery within four days of the subarachnoid haemorrhage, and those undergoing surgery after this period. Patients were allocated to the earlier surgical group if they sustained a rebleed or died within four days of the subarachnoid haemorrhage while awaiting their surgery.

\section{STATISTICAL ANALYSIS}

Analysis of differences between phase 1 and 2 patients, and between the early and late surgical groups within phase 2 were analysed using contingency tables, Fisher's exact test, and the $\chi^{2}$ test of homogeneity. The duration of neurosurgical hospital stay was analysed using analysis of variance (unpaired $t$ test).

\section{Results}

Demography and transfer (table 1)

Table 1 shows the demographic data and timings of transfer to the regional neurosurgical unit. In 18 patients from phase 2 , there was a significant delay either in the patient presenting to the general practitioner, or in the referral of the patient to the local district general hospital. In Phase 1 of the study the different factors delaying transfer could not be accurately determined from the clinical records.

\section{Investigation}

Eighty eight per cent of patients in phase 1 and $93 \%$ of phase 2 patients had evidence of blood on initial CT. A positive lumbar puncture confirmed the diagnosis in the remaining patients. Ninety one per cent of phase 1 patients and $88 \%$ of phase 2 patients underwent angiography on median day 4 (range 0 to 48 ) and day 1 
Table 1 Demographic data from phase 1 and 2

\begin{tabular}{llc}
\hline & Phase 1 & Phase 2 \\
\hline No of patients (n) & 92 & 129 (early management $\mathrm{n}=62$ ) \\
& 58 & 74 \\
Case load per year & $42: 58$ & $40: 60$ \\
M:F & $54(19-79)$ & $53(19-81)$ \\
Median age (y) (range) & $4(0-18)$ & $1(0-17)$ \\
Median day of transfer (range) & &
\end{tabular}

(range 0 to 14 ) respectively. In two patients from phase 2 the initial angiogram failed to show the cause of the subarachnoid haemorrhage. In these patients subsequent angiography (in one patient angiography was performed three times) disclosed an aneurysm. Two patients with sylvian fissure haematomas in the second phase of the audit underwent middle cerebral artery aneurysm clipping without a pre-operative angiogram. The distribution of aneurysms in the two phases of the study was similar, with internal carotid aneurysms occurring most often (39\%) followed by anterior communicating artery aneurysms $(30 \%)$, middle cerebral artery aneurysms $(25 \%)$, and finally posterior circulation aneurysms (6\%). Multiple aneurysms occurred in $20 \%$ of phase 1 patients and $22 \%$ of phase 2 patients.

\section{SEVERITY OF THE SUBARACHNOID \\ HAEMORRHAGE (FIG 1)}

Figure 1 shows the severity of the subarachnoid haemorrhage at the time of admission to the neurosurgical unit. There was a significantly greater number of patients presenting in WFNS grade 1 during phase 1 than during phase 2 $(P<0.03)$. The distribution of severity of subarachnoid haemorrhage between the early and late groups of phase 2 was not different.

\section{MANAGEMENT}

Perioperative resuscitation

Sixty eight per cent of patients in phase 1 received some preoperative intravenous fluids. The volume of fluid given to these patients could not be determined retrospectively from the case notes. However, no fixed regime was employed. There was no recorded use of preoperative colloids, and no case where central venous pressure monitoring was used to guide fluid management. In phase 2 of the audit the intravenous crystalloid/colloid protocol was adhered to in $80 \%$ of patients. In the remaining $20 \%$ an oral consumption $>2.51 / 24 \mathrm{~h}$ was achieved.

Timing of aneurysm surgery (fig 2, table 2) In phase 1 of the audit the median day of surgery was day 12 (range $0-85, \mathrm{n}=75$ ). In the phase 2 the median day of surgery was day 4 (range $0-39, n=109$ ). The timing of surgery in phase 2 was grouped into those

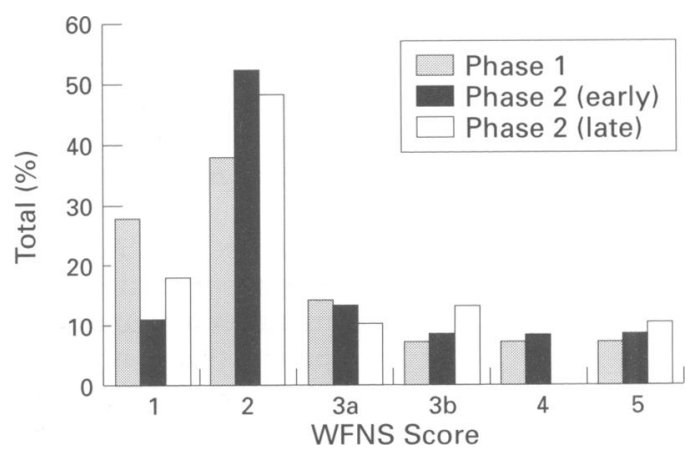

Figure 1 World Federation of Neurological Surgeons (WFNS) score on day of admission to the neurological unit.

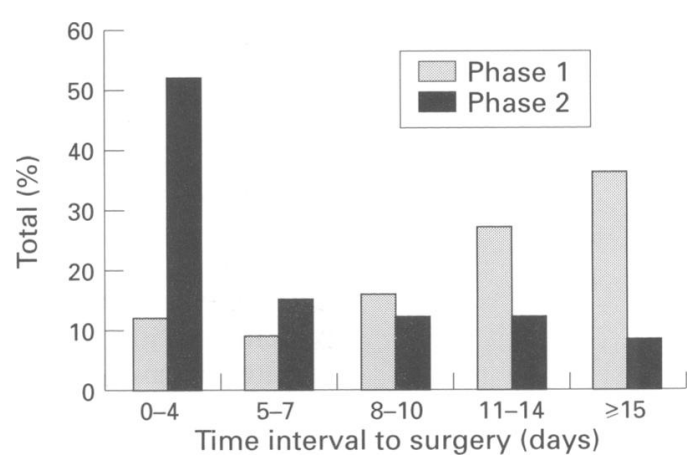

Figure 2 Timing of surgery in all operated patients.

patients undergoing surgery within four days of the subarachnoid haemorrhage (58 cases) and those undergoing surgery after this interval (51 cases). In the group of patients undergoing early surgery the median time to surgery was two (range 0-4) days, compared with nine (range 5-39) days in the delayed surgery group.

\section{SURGICAL FACTORS}

Perioperative ventricular drainage was performed in seven patients during phase 1 , and eight during phase 2 . Intraoperative aneurysm rupture occurred in five patients $(7 \%)$ in phase 1 and in 17 patients $(16 \%)$ in phase 2 . In phase 1 of the audit $31 \%$ of operations were performed by a surgical trainee (under consultant supervision) compared with $60 \%$ in phase 2 .

\section{POSTOPERATIVE ISCHAEMIA (TABLE 2)}

Postoperative ischaemia was not significantly different between the phases of the audit. However, there was a tendency towards a reduced incidence in phase 2 patients undergoing early surgery compared with late $(9 \% v$ $23 \% ; P=0.06$ ).

\section{Rate of rebleed}

During the 40 months of this study 29 patients sustained a rebleed. The median day of

Table 2 Timing of surgery and incidence of perioperative ischaemia

\begin{tabular}{lllll}
\hline & $\begin{array}{l}\text { Phase 1 } \\
n(\%)\end{array}$ & $\begin{array}{l}\text { Phase 2 (all patients) } \\
n(\%)\end{array}$ & $\begin{array}{l}\text { Phase 2: early management } \\
n(\%)\end{array}$ & $\begin{array}{l}\text { Phase 2 delayed management } \\
n(\%)\end{array}$ \\
\hline Patients having surgery & $75(82)$ & $109(84)$ & $58(94)$ & $51(76)$ \\
Median day of surgery (range) & $12(0-85)$ & $4(0-39)$ & $2(0-4)$ & $9(5-39)$ \\
Postoperative ischaemia & $17(23)$ & $16(15)$ & $5(9)$ & $11(23)$ \\
\hline
\end{tabular}


rebleed was day 9 (range 1-35). The overall mortality of rebleeds was $79 \%$. Early surgery in phase 2 of the study virtually eradicated rebleeding, which occurred in only one patient in this group.

Outcome (figs 3 and 4)

Figures 3 and 4 show that the surgical and management outcome scores in all groups of patients were not significantly different. There was a tendency towards lower mortality in the phase 2 early group $(11 \% v 22 \%, P=0 \cdot 11)$. Table 3 shows the actual causes of death. A high proportion of patients in the phase 2 early group died as a consequence of the initial haemorrhage which offset the reduced mortality from rebleeding when compared with the late phase 2 group. Rebleeding was the main cause of death in patients undergoing late surgery $(61 \%$ in phase $1 ; 73 \%$ in late phase 2 patients).

\section{Resources}

The earlier transfer and investigation of patients with subarachnoid haemorrhage resulted in an increase of $28 \%$ in numbers of patients admitted to the neurosurgical unit with aneurysmal subarachnoid haemorrhage. Patients undergoing angiography rose by $37 \%$, and those undergoing aneurysm surgery increased by $45 \%$ during phase 2 of the audit.
Figure 3 Glasgow outcome score three months after operation (surgical patients only).

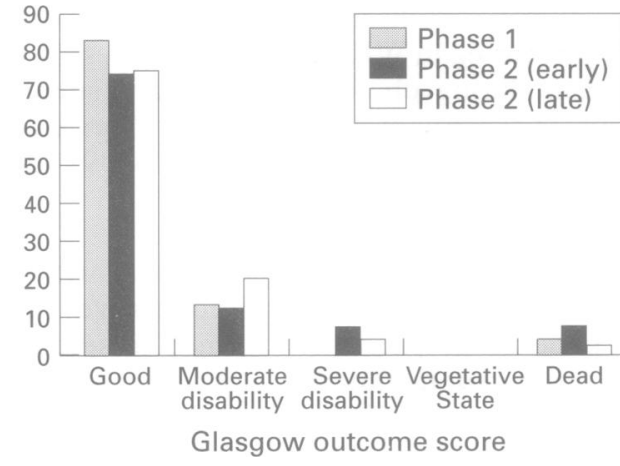

Figure 4 Glasgow outcome score three months after operation or three months after the initial haemorrhage in patients not undergoing aneurysm surgery (all patients).
The total duration of hospital stay $(15 \cdot 8 ; 95 \%$ confidence interval ( $95 \% \mathrm{CI}$ ) $13 \cdot 1-18 \cdot 5$ days) was shorter for survivors of early surgery in the second phase of the study compared with those of late surgery $(25 \cdot 7 ; 95 \%$ CI: $21 \cdot 6-29 \cdot 8$ days), or those surviving from phase $1(24 \cdot 8$; 95\% CI 21.9-27.7 days). The differences between early and late groups were highly significant $(P<0.00001)$.

\section{Discussion}

The overall management outcome between phase 1 and phase 2 patients was very similar. Thus despite operating earlier during phase 2 of the study, morbidity was not increased. This contrasts with data from other studies, ${ }^{9}$ and suggests that surgery can be performed with acceptable morbidity and mortality in the early post-subarachnoid haemorrhage phase when modern medical and surgical techniques are followed. These include the routine use of prophylactic nimodipine, giving an appropriate intravenous fluid regime perioperatively, and attention to microsurgical techniques.

Historically, the risk of rebleeding has been declared maximal within the first 48 hours of the initial ictus. ${ }^{124}$ Thus previous efforts at reducing the rebleed rate has involved emergency surgery within a few hours of admission. ${ }^{13-19}$ The outcome from such emergent procedures was variable and has not gained widespread favour among vascular neurosurgeons. The reasons for this are not understood, but patients may be ill prepared for surgery at this stage in terms of reduction of circulating blood volume and unrecognised metabolic disturbances. Blood volume determinations in patients after a subarachnoid haemorrhage show that circulating blood volume is frequently diminished..$^{33-36}$ In addition, some patients develop hyponatraemia. ${ }^{36}{ }^{37}$ These factors are important in the development of ischaemic deficits, and correction can result in clinical improvement. ${ }^{26} 278$ In defining an early management strategy, we have taken into account these factors, and effected fluid resuscitation at an early stage as a prophylactic measure against cerebral ischaemia in all patients in the prospective study groups. In addition, we treat all patients with subarachnoid haemorrhage with calcium channel blockers for optimal preoperative preparation. We consider out of hours surgery as ill advised considering the need for careful microsurgical attention. Our present data show that despite expeditious transfer by (median) day 1 postictus during phase 2 , rebleeding within the first 72 hours never occurred, thus the need for "ultra" early surgery does not seem necessary

Table 3 Cause of death after aneurysmal subarachnoid haemorrhage

\begin{tabular}{lcccc}
\hline & $\begin{array}{l}\text { Phase 1 } \\
n(\%)\end{array}$ & $\begin{array}{l}\text { Phase 2 (all patients) } \\
n(\%)\end{array}$ & $\begin{array}{l}\text { Phase 2: early management } \\
n(\%)\end{array}$ & $\begin{array}{l}\text { Phase 2 delayed management } \\
n(\%)\end{array}$ \\
\hline $\begin{array}{l}\text { Total no of deaths } \\
\text { Cause of death: }\end{array}$ & $18(20)$ & $22(17)$ & $7(11)$ & $15(22)$ \\
$\quad$ Initial bleed & $2(11)$ & $4(18)$ & $3(43)$ & $1(7)$ \\
Rebleed & $11(61)$ & $12(55)$ & $1(14)$ & $11(73)$ \\
Ischaemia & $2(11)$ & $5(23)$ & $2(28)$ & $3(20)$ \\
Other & $3(17)$ & $1(5)$ & $1(14)$ & $0(0)$ \\
\hline
\end{tabular}


in patients with subarachnoid haemorrhage from our catchment population.

The tendency towards lower mortality and perioperative ischaemia in the early operated group of phase 2 patients needs further discussion. Despite a very similar distribution of severity of subarachnoid haemorrhage within each group, perioperative ischaemia and mortality seemed lower in patients operated on earlier although this did not reach significance. A disproportionate number of patients dying from the initial effects of the bleed in the early phase 2 group may be one reason why this did not translate into a significant reduction in mortality. In addition, two patients presenting with decompensating space occupying haematomas demanding urgent surgery, one of whom was severely disabled, were automatically placed in the early surgery group.

Perioperative ischaemia seemed to be reduced in phase 2 patients compared with those in phase 1, particularly in the early operated group although this just failed to reach significance. Because inaccuracies inherent within a mixed retrospective and prospective study are likely to be biased against phase 2 patients in that recording of perioperative ischaemia will not have been as accurate in the retrospective group, we are content that earlier surgery did not increase the morbidity from ischaemia. A larger prospective randomised trial will be required to determine whether this translates into significant reductions in morbidity and mortality.

A policy to transfer patients at an earlier stage after the subarachnoid haemorrhage resulted in an increased neurosurgical admission rate, from 58 to 74 patients a year in phase 2 of the audit. This may reflect a response to an "open door" policy for the early transfer of all patients with subarachnoid haemorrhage in phase 2 . In phase 1 of the study, some patients may have died awaiting transfer to the neurosurgical unit. Surgery delayed beyond four days after the initial haemorrhage was associated with a high rebleed rate in phase 2 patients. As the median day of transfer during phase 1 was day 4 , it is likely that the management outcome in phase 1 conceals significant mortality in patients while waiting in their referring hospitals, and also explains the higher incidence of phase 2 patients dying from the effects of the initial bleed.

The incidence of intraoperative aneurysm rupture was higher in phase 2 of the study, but similar in early and late treatment subgroups. The reasons for this are unclear, but may relate to the fragility of the recently formed thrombus in the early surgery patients. Further, there was an increased number of procedures performed by trainees in phase 2 . However, intraoperative aneurysm rupture did not adversely affect morbidity and mortality in this series. Again the reasons for this are unclear. Adequate proximal vessel exposure and the use of temporary clips to control these feeding arteries allows the dissection to continue in a controlled fashion without necessarily resorting to "salvage" surgery and blind placement of clips. These techniques are being increasingly used and may help to account for the low incidence of unfavourable outcomes after inadvertent surgical rupture which has been noted by others. ${ }^{39}$

The increase in neurosurgical workload in the second phase of the study has financial implications that should be set in the overall context of care from the initial ictus to final outcome. ${ }^{40}$ The total duration of stay in the neurosurgical unit was significantly reduced in patients undergoing early surgery. We could identify no change in hospital related resources to account for this finding, except that of promoting earlier surgery. There had been no change in the level of patient support during recovery, and no increased pressure to discharge patients earlier. We are therefore confident in stating that earlier surgery has reduced overall hospital stay very significantly, and that this has been achieved without subjecting the patient to increased risks of morbidity. Although we have not conducted a detailed cost analysis, it is probable that the reduced hospital stay represents cost savings in the surgical treatment of aneurysmal subarachnoid haemorrhage.

In summary, despite the difficulties inherent in a mixed retrospective and prospective study the data obtained provide convincing evidence that, contrary to historical concern, early surgery for aneurysmal subarachnoid haemorrhage can be carried out safely. This approach also seems to reduce the time for patient recovery and inpatient stay. We present the data to stimulate other centres to prospectively analyse their management results in the treatment of subarachnoid haemorrhage.

1 Crawford MD, Sarner M. Ruptured intracranial aneurysm. Community study. Lancet $1965 ;$ ii: $1254-7$.

2 Pakarinen S. Incidence, aetiology and prognosis of primary subarachnoid haemorrhage. Acta Neurol Scand 1967; 3(suppl 29):1-128.

3 Vermeulen $M$, Lindsay $\mathrm{KW}$, Cheah MF, Hijdra A, Muizelaar JP, Schannong M, et al. Antifibrolytic treatment in subarachnoid haemorrhage. New Engl $f$ Med 1984;311:432-7.

4 Locksley HB. Report on the co-operative study of intracranial aneurysms and subarachnoid haemorrhage. Section $\mathrm{V}$, part II, natural history of subarachnoid haemorrhage, intracranial aneurysms and arteriovenous malformations. f Neurosurg 1966;25:321-68.

5 Broderick JP, Brott, Duldner JE, Tomsick T, Leach A. Initial and recurrent bleeding are the major causes of death following subarachnoid haemorrhage. Stroke death following

6 Jane JA, Winn HR, Richardson AE. The natural history of intracranial aneurysms. Rebleeding rates during the acute and long-term period and implications for surgical management. Clin Neurosurg 1977;24:76-84.

7 Saito I, Ueda Y, Sano K. Significance of vasospasm in the treatment of ruptured intracranial aneurysms. $f$ Neurosurg 1977;47:412-29.

8 Koos WT, Perneczky A. Timing of surgery for ruptured aneurysms-experience from 800 consecutive cases. Acta Neurochir 1982;63:125-33.

9 Kassell NF, Torner JC, Haley EC, Jane JA, Adams HP, Kongable GL, et al. The International Co-operative Study on the Timing of Aneurysm Surgery. Part 1: overall management results. $\mathcal{F}$ Neurosurg 1990;73:18-36.

10 Dorsch NW. Surgery for cerebral aneurysms, an eight year experience. Med f Aust 1984;141:18-21.

11 Pickard JD, Murray GD, Illingworth R, Shaw MDM, Teasdale GM, Foy PM, et al. Effect of oral nimodipine on cerebral infarction and outcome after subarachnoid on cerebral infarction and outcome after subarachnoid 1989;298:636-42.

12 Sano K, Saito I. Timing and indication of surgery for ruptured intracranial aneurysm with regard for cerebral vasospasm. Acta Neurochirur (Wein) 1978;41:49-60

13 Yoshimoto T, Uchida K, Kaneko U, Kayama T, Suzuki J. An analysis of the follow-up results of 1000 intracranial saccular aneurysms with definitive surgical treatment. $\mathcal{f}$ Neurosurg 1979;50:152-7. 
14 Suzuki J, Onuma T, Yoshimoto T. Results of early operations on cerebral aneurysms. Surg Neurol 1979;11: 407-12.

15 Kassell NF, Torner JC, Jane JA, Haley EC, Adams HP. The International Co-operative Study on the Timing of Aneurysm Surgery. Part 2: surgical results. I Neurosurg 1990;73:37-47.

16 Kassell NF, Boarini DJ, Adams HP, Sahs AL, Graf CJ, Torner JC, et al. Overall management of ruptured aneurysm: comparison of early and late operation. Neurosurgery 1981;9:120-8

17 Ljunggren, Brant L, Kagstrom E, Sundbarg G. Results of early operations for ruptured aneurysms. I Neurosurg $1981 ; 54: 473-9$.

18 Ljunggren B, Saveland S, Brandt L, Zygmunt S. Early operation and overall outcome in aneurysmal subarachnoid haemorrhage. $\mathcal{F}$ Neurosurg 1985;62:547-51.

19 Mizukami M, Kawaqse T, Usami T, Tazawa T. Prevention of vasospasm by early operation with removal of subarachnoid blood. Neurosurgery 1982;10:301-7.

20 Bailes JE, Spetzler RF, Hadley MN, Baldwin HZ. Management morbidity of poor-grade aneurysm patients. Management morbidity of po

21 Ohman J, Heiskanen $\mathrm{O}$. Timing of operation of ruptured supratentorial aneurysms: a prospective randomised supratentorial aneurysms: a prosp
study. $\mathcal{F}$ Neurosurg 1989;70:55-60.

22 Graham DI, MacPherson P, Pitts LH. Correlation between angiographic vasospasm, hematoma, and ischaemic brai damage following SAH. $\mathcal{F}$ Neurosurg 1983;59:223-30

23 Weir B, Grace M, Hansen J, Rothberg C. Time course of vasospasm in man. $\mathcal{F}$ Neurosurg 1978;48:173-8.

24 Kosnick EJ, Hunt W. Postoperative hypertension in the management of patients with intracranial arterial aneurysms. 7 Neurosurg $1976 ; 45: 148-54$

25 Kassell NF, Drake CG. Timing of aneurysm surgery. Neurosurgery 1982;10:514-9.

26 Kassell NF, Peerless SJ, Durward OJ, Beck DW, Drake CG, Adams HP. Treatment of ischemic deficits from vasospasm with intravascular volume expansion and vasospasm with intravascular volume expansion and
induced arterial hypertension. Neurosurg 1982;11: induced

27 Awad IA, Carter LP, Spetzler RF, Medina M, Williams FW Jr. Clinical vasospasm after subarachnoid hemorrhage: response to hypervolemic hemodilution and arterial hypertension. Stroke 1987;18:365-72.

28 Hasan D, Vermeulen M, Wijdicsk EFM, Hijdra A, van
Gijn J. Effect of fluid intake and antihypertensive treatment on cerebral ischaemia after subarachnoid haemorrhage. Stroke 1989;20:1511-5.

29 Whitfield PC, Kirkpatrick PJ, Moss $H$, O'Hare D. The effects of earlier transfer, fluid rescusitation and surgery on the outcome of patients with aneurysmal subarach noid haemorrhage. $\mathcal{f}$ Neurol Neurosurg Psychiatry 1994: noid haem

30 Teasdale GM. A universal subarachnoid haemorrhage scale: report of a committee of the World Federation of Neurological Societies. If Neurol Neurosurg Psychiatry 1988;51:1457.

31 Jennett B, Bond $M$. Assessment of outcome after sever brain damage. A practical scale. Lancet 1975;ii:480-4.

32 Solomon RA, Fink ME, Lennihan L. Early aneurysm surgery and prophylactic hypervolaemic hypertensive therapy for the treatment of aneurysmal subarachnoid hemorrhage. Neurosurgery 1988;23:699-704.

33 Nelson RJ, Roberts J, Ackery DM, Pickard JD. Measurement of total circulating blood volume following subarachnoid haemorrhage: methodological aspects. $尹$ Neurol Neurosurg Psychiatry 1987;50:1130-5.

34 Kudo T, Suzuki S, Iwabuchi T. Importance of measuring the circulating blood volume in patients with cerebral vasospasm after subarachnoid hemorrhage. Neurosurgery

35 Solomon RA, Post KD, McMurtry JG. Depression of circulating blood volume in patients after subarachnoid hemorrhage: implications for the management of symptomatic vasospasm. Neurosurgery 1984;15:354-61.

36 Wijdicks EF, Vermeulen M, Ten Haaf JA, Hijdra A Bakker WH, van Gijn J. Volume depletion and naturesis in patients with a ruptured intracranial aneurysm. $A n n$ Neurol 1985;18:211-6.

37 Lolin Y, Jackowski A. Hyponatraemia in neurosurgica patients: diagnosis using derived parameters of sodium patients: diagnosis using derived parameters of sodium

38 Maroon JC, Nelson PB. Hypervolemia in patients with subarachnoid hemorrhage: therapeutic implications. Nubarachnoid hemorrhage:

39 Jamjoom A, Jamjoom ZA, Stranjalis G, Cummins B Torrens $M$. The outcome of surgery of aneurysmal subarachnoid haemorrhage. $B r f$ Clin Pract 1993;47:136-40.

40 Pickard JD, Bailey S, Sanderson H, Rees M, Garfield JS Steps towards cost-benefit analysis of regional neurosurgical care. BMF 1990;301:629-35. 